\title{
Betinho e as ONGs: sociogênese de uma nova militância
}

\section{Fernando Lima Neto*}

\section{Resumo}

O presente artigo explora uma dimensão específica do desenvolvimento recente da sociedade civil no Brasil: o campo das ONGs. A formação desse campo é apresentada como consequência não intencional da aproximação de ativistas católicos com ideologias de esquerda, em meados do século XX. A noção de sociogênese permite articular o plano macroestrutural de formação do campo das ONGs no Brasil ao plano biográfico de um dos seus principais atores, Herbert de Souza, conhecido popularmente como Betinho. Sustento que existe uma relação de forte correspondência entre esses dois planos. A biografia de Betinho sintetiza, em um plano individual, boa parte das transformações que estiveram subjacentes à emergência do campo das ONGs no Brasil: (i) a aproximação e o posterior afastamento entre religião e política, (ii) a diversificação das pautas e agendas de reivindicação e (iii) a reinvenção de laços de emoção com a política fora das arenas convencionais de representação. A trajetória de Betinho individualiza e imprime contornos carnais a transformações estruturais profundas na vida política nacional, tanto no que diz respeito a suas instituições quanto à cultura política. A formação do campo das ONGs foi um resultado não programado desse processo e possui relações umbilicais com a formação do ativismo político de Betinho.

Palavras-chave: religião e política. estrutura e ação. sociedade civil. ONGs. Betinho.

\footnotetext{
*Pontifícia Universidade Católica do Rio de Janeiro, Rio de Janeiro, RJ, Brasil.
} 


\section{Betinho and the NGOs: sociogenesis of a new kind of activism}

\section{Abstract}

This article discusses a specific dimension of the recent development of civil society in Brazil: the field of NGOs. The formation of this field is presented as an unintended consequence of the approach of Catholic activists with left wing ideologies in the middle of the twentieth century. I build on the notion of sociogenesis in order to articulate the macro-structural sphere of formation of the field of NGOs in Brazil to the biographical sphere of one of its main actors, Herbert de Souza, popularly known as Betinho. There is a strong correspondence between both domains. Betinho's biography synthesizes on an individual level a large part of the transformations that underpinned the emergence of the NGO field in Brazil: (i) the approximation and subsequent separation between religion and politics, (ii) the diversification of advocacy themes and agendas, and (iii) the re-creation of emotional links with politics outside the conventional arenas of representation. Betinho's trajectory individualizes and imprints bodily contours to profound structural transformations of national political life, both related to institutions and to the political culture. The formation of the NGO field was an unexpected result of this process is closely related to the formation of Betinho's political activism.

Keywords: religion and politics. structure and action. civil society. NGOs. Betinho.

\section{Introdução: a política entre estruturas e ações}

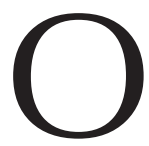
aumento da desconfiança popular nas instituições de representação é um fenômeno que, desde o último quarto do século passado, pode ser observado em boa parte do mundo democrático (Manin, 1996; Crozier; Huntington; Watanuki, 1975). No Brasil, esse fenômeno tem se intensificado ainda mais nas últimas décadas (Moisés, 2010). Partidos políticos, sindicatos, entidades de classe e agremiações estudantis são, muitas vezes, apontados como instituições associadas a práticas de corrupção, pouco eficientes no seu propósito de representação. Esse sentimento generalizado de descrença nas instituições de representação tem estimulado, sobretudo entre os jovens, o aparecimento de muitas experiências de 
mobilização política construídas fora das arenas mais convencionais da representação. No Brasil, a emergência de fenômenos como as organizações não governamentais (ONGs) e os novos movimentos sociais são exemplos de transformações relativamente recentes na política que apontam para a revisão crítica de fundamentos importantes da teoria democrática, como as próprias noções de representação e participação. O caso das ONGs é revelador. Em meio às diferentes definições do conceito na literatura especializada, persiste um entendimento relativamente consensual sobre três critérios gerais de negação: não pertencem ao Estado, não visam ao lucro e não são representativas. Os dois primeiros critérios são suficientemente coerentes, mas muito poderia ser discutido sobre o terceiro.

Por um lado, se mantemos no horizonte o debate contratualista que fundamentou a compreensão moderna de representação, de fato, não é possível dizer que as ONGs sejam representativas. O entendimento moderno de representação consiste em uma autorização formal que um representado, mediante processo eleitoral, concede a um representante (Pitkin, 2006; Hobbes, 2014; Bobbio; Bovero, 1996). Como uma ONG não é eleita, não é representativa neste sentido. Por outro lado, fenômenos como as ONGs oferecem a oportunidade de atualizar a reflexão sobre a própria ideia de representação, como acontece na discussão sobre advocacy (Keck; Sikkink, 1999; MacAdam et al., 1996). No Brasil, alguns autores apostam na emergência de novas formas de representação, cujos critérios definidores não estão mais condicionados a uma autorização formal via processo eleitoral, mas são construídos em torno da afirmação de outros critérios, tais como, por exemplo, a expertise, a afinidade ou o compromisso (Avritzer, 2007; Gurza-Lavalle; Houtzager; Castello, 2006). Por sua vez, outros autores interpretam esse ativismo sem mandato eleitoral como uma ameaça ao bom funcionamento da democracia. O fato de não disporem de um mandato tornaria inviável o exercício de accountability nessas pretensas formas de representação (Miguel, 2014).

Neste artigo, proponho analisar uma questão diferente, e mesmo anterior a essa. Ao invés de tratar dos efeitos que o fenômeno das ONGs 
suscita na democracia no Brasil, detenho-me sobre o processo histórico que tornou possível a formação desse fenômeno. Estou interessado em compreender a forma como mudanças estruturais no campo da política nacional, em especial o fortalecimento da democracia e da sociedade civil no fim do século passado, foram ajustadas por instituições e atores que conduziram esse processo. Mais importante, detenho-me sobre a emergência de um novo modelo de ativismo político que é, aqui, apresentado como consequência não intencional da aproximação de ativistas católicos com ideologias de esquerda. Dito de outro modo, o objetivo do texto é fazer uma sociogênese do desenvolvimento da sociedade civil no Brasil, concentrando a análise na formação do campo das ONGs. Particularmente, proponho articular o plano macroestrutural de formação do campo das ONGs no Brasil ao plano biográfico de um dos seus principais ativistas, Herbert de Souza, conhecido popularmente como Betinho. Sustento que existe uma relação de forte correspondência entre esses dois planos. A biografia de Betinho sintetiza, em um plano individual, boa parte das transformações que estiveram subjacentes à emergência do campo das ONGs no Brasil: a aproximação e o posterior afastamento entre religião e política, a diversificação das pautas e agendas de reivindicação e a reinvenção de laços de emoção com a política fora das arenas convencionais de representação.

A noção de sociogênese é um artefato analítico operado por Norbert Elias para vincular biografias individuais e processos históricos de longa duração, como, por exemplo, no caso de sua obra sobre Mozart ${ }^{1}$ (Elias, 1995). Elias considerou a vida de Mozart como um microprocesso no seio de um período de transformações estruturais que ocorriam na segunda metade do século XVIII. Por um lado, as tensões e dilemas que marcaram a vida de Mozart retratavam uma concepção de arte que até então era hegemônica no mundo social, mas que, por outro lado, foi intensamente transformada, em parte como consequência das contribuições individuais do

\footnotetext{
${ }^{1}$ Apresentando a trajetória de vida de Mozart, Elias analisa as tensões que, na segunda metade do século XVIII, marcaram o remanejamento dos equilíbrios de poder entre o grupo establishment cortesão e os outsiders burgueses na Áustria (Elias, 1995).
} 
próprio artista. Ação e estrutura são, portanto, apresentados como processos que se condicionam mutuamente. Proponho partir desta perspectiva de condicionamento mútuo entre estrutura e ação para analisar as implicações dialógicas entre a biografia de Betinho e a formação do campo das ONGs no Brasil. Sustento que, assim como aconteceu com Mozart no universo da arte, a biografia de Betinho antecipa dramaticamente questões importantes do universo da política, que viriam a transformar todo o campo da sociedade civil e do ativismo político no Brasil. A perspectiva da sociogênese permite, portanto, analisar o processo de formação do campo das ONGs no Brasil na escala de um de seus principais atores. As escolhas e os desafios que marcaram a vida de Betinho refletem de maneira cristalina as transformações que tornaram possível a formação de um novo tipo de militância política, associada a novos objetos e formas de mobilização.

Neste artigo, recorro a uma biografia, relatos de amigos e três depoimentos de Betinho feitos em momentos distintos de sua vida. Partindo da perspectiva da sociogênese, analiso esse material dentro da cronologia que diz respeito ao processo de formação das ONGs no Brasil. A biografia intitulada Betinho: sertanejo, mineiro, brasileiro, de Carla Rodrigues, é uma publicação que reúne de modo exaustivo e com riqueza de detalhes estórias, relatos e outros registros de informação sobre a vida de Betinho (Rodrigues, 2007). Essa é sua biografia mais completa, escrita por uma exassessora, que realizou trabalho de investigação histórica dirigido como subsídio para elaboração de uma obra literária. Já Memórias do exílio (1976) e Revoluções de minha geração (1994) são dois depoimentos de Betinho em momentos distintos de sua vida. O primeiro ocorreu no Canadá, durante sua experiência no exílio. Trata-se de um depoimento encomendado pelos historiadores Pedro Cavalcanti e Jovelino Ramos a intelectuais e ativistas brasileiros expatriados (Cavalcanti; Ramos, 1976). No segundo, já na década de 1990, recebeu o jornalista François Bougon para uma série de entrevistas que seriam editadas em francês e português. Por sua vez, Estreitos nós é uma coletânea de textos escritos por amigos e pessoas próximas após sua morte (Souza, 2001). Os fatos mencionados nesta 
reconstituição da biografia de Betinho estão especialmente amparados nessas quatro referências bibliográficas.

Na próxima seção, parto de uma breve exposição sobre o longo processo de laicização religiosa da promoção de assistência social no Ocidente para contextualizar a gênese histórica de formação do campo das ONGs no Brasil. Ao longo do século XX, três grandes transformações históricas tornaram possível a emergência desse campo. Primeiramente, a aproximação de instituições leigas católicas com as ideologias de esquerda e os movimentos sociais entre as décadas de 1940 e 1960. Em seguida, no decurso da década de 1980, a segunda transformação diz respeito ao rompimento das antigas instituições leigas católicas com os movimentos sociais. A terceira grande transformação ocorreu durante a década de 1990, com a consolidação e popularização da identidade ONG em um contexto marcado pela cooperação internacional no ambiente da sociedade civil. Essas transformações ajudaram a consolidar os valores da justiça social, da filantropia e da ecologia como marcos simbólicos do universo das ONGs no Brasil (Lima Neto, 2016). Na seção seguinte, relaciono o processo estrutural de formação do campo das ONGs no Brasil com a trajetória individual de Betinho. Por um lado, analiso os efeitos das transformações estruturais do campo da esquerda católica na formação política de Betinho: sua militância católica e seu posterior rompimento com a religião. Por outro lado, enfatizo sua contribuição individual na estruturação do campo das ONGs no Brasil, em particular sua iniciativa de estabelecer redes, encampar novos temas de reivindicação política e fundar instituições pioneiras neste campo. A seção de encerramento sumariza os pontos mais importantes desse exercício de sociogênese. 


\section{A formação do campo das ONGs no Brasil: da caridade cristã ao profissionalismo engajado}

Se considerarmos assistência social privada como a promoção não estatal de auxílio a indivíduos ou grupos em situação de risco ou exclusão, sua gênese histórica remete às práticas de caridade promovidas pela Igreja Católica desde, pelo menos, a Idade Média. O mundo medieval ocidental tinha na Igreja a principal fonte de legitimação da ordem social. Nessas condições, um dos princípios fundamentais do cristianismo, o valor da caridade, ocupava uma posição central na organização social, seja no plano das instituições ou das práticas cotidianas. A consagração da Igreja como pedra fundamental na construção da ordem social implicou na multiplicação das práticas e instituições de caridade cristã a partir do século V (Mesgravis, 1976; Neyron, 1927).

Foi apenas entre os séculos X e XI que a promoção de assistência social a mendigos, enfermos, órfãos e inválidos deixou de ser uma prerrogativa exclusiva da Igreja. O processo de expansão marítimo-comercial, a urbanização e o surto demográfico durante a baixa Idade Média foram condições que levaram a nobreza a criar em seus feudos hospitais, asilos, albergues e leprosários. Alguns nobres se encarregavam eles próprios da administração dessas instituições, enquanto outros delegavam esta tarefa às várias ordens hospitalares criadas durante e após as Cruzadas. Essas ordens hospitalares tinham o objetivo de gerenciar as instituições cristãs de promoção de assistência social (Correia, 1999). Posteriormente, o período que se estende entre os séculos XII e XIII representou um grande marco no desenvolvimento dessas instituições, quando segmentos burgueses começaram a se envolver no gerenciamento das mesmas, aumentando assim a participação dos leigos católicos, isto é, cristãos que não pertencem ao clero (Russell-Wood, 1981; Veilleux, 1968).

Durante os séculos XII e XIII, as instituições medievais de promoção de assistência social passaram por grandes transformações. Católicos leigos pertencentes à burguesia emergente passarem a disputar com o clero e a 
nobreza as funções de comando dessas instituições. Estava, assim, firmado o longo processo, iniciado já nos séculos X e XI, e ainda hoje em curso, de laicização religiosa das práticas de assistência social no mundo ocidental. A noção de laicização religiosa aponta para o horizonte dos valores cristãos que orientaram a formação do campo da assistência social no Ocidente. A tensão entre esses dois termos revela muito mais do que um simples oximoro. Sustento que a ideia de laicização religiosa reflete com relativa precisão a condição ambivalente das práticas de assistência social que se apresentam como seculares, mesmo sendo religiosamente motivadas. Esse fenômeno já estava presente na Idade Média, com o ativismo dos leigos cristãos, pessoas que assumem uma vinculação pessoal com o cristianismo, mas que refutavam votos e prescrições religiosas nas atividades públicas que desempenham em prol dos outros. Uma característica importante e duradoura (até hoje presente) nesse tipo de engajamento é a relação tensa que as pessoas travam com valores religiosos e laicos, muitas vezes apresentando como secular aquilo que no nível pessoal é vivenciado como religioso.

Além da entrada dos leigos e da especialização no domínio de atuação, outra condição histórica importante para o processo de laicização-religiosa da assistência social no ocidente aconteceu um pouco mais tarde, nos séculos XIV e XV, com a centralização do poder do Estado. Nessa época, as relações de poder que garantiam o equilíbrio tenso entre Igreja, Estado e sociedade na promoção de assistência social passaram a tender para o lado do Estado. Durante toda a Antiguidade e na maior parte da Idade Média, a Igreja exerceu uma posição soberana no controle dessas instituições. Entretanto, nos séculos seguintes, o sucesso do Absolutismo na Europa consolidou a posição do Estado como novo princípio organizador da vida social, deslocando a Igreja para uma posição secundária, ainda que importante na legitimação da ordem social. Dito de outro modo, se até então a história da promoção de assistência social podia ser contada sob a ótica do desenvolvimento da Igreja, agora ela passa a se confundir cada vez mais com a história de formação dos Estados nacionais. Assim, a fim 
de prosseguir essa breve recapitulação macro histórica, passamos agora a seguir o curso do tempo e dos eventos que sucedem o século XV através de um corte nacional-português para chegar ao desenvolvimento brasileiro.

Após ter passado por um cenário de muita fome, pestes e guerras no século XIV, Portugal, no século XV, estava repleto de hospitais, leprosários e irmandades de caridade. Inevitavelmente, começou a haver uma superposição de atividades assistenciais, o que muitas vezes indicava a necessidade de uma política oficial de promoção da caridade. O primeiro passo dado nessa direção ocorreu em 1479, quando o príncipe D. João interpelou o Vaticano e obteve uma bula papal autorizando a fusão de todos os pequenos hospitais, asilos e albergues de Lisboa em um único edifício, administrado pela Coroa (Russell-Wood,1981; Mesgravis; 1976). Certamente, não se tratava ainda de uma obrigação social do Estado, o que só viria acontecer mais tarde a partir do século XIX, mas pavimentava o caminho nessa direção. Os séculos XV e XVI foram, portanto, decisivos para evolução histórica da promoção de assistência social, pois introduziram um novo ator, o Estado. Progressivamente durante esse período, as ordens monásticas passaram a disputar com a corte a fundação de hospitais, albergarias e leprosários (Russell-Wood, 1981).

É neste estágio moderno, implicado com a formação dos Estados nacionais, que o processo de laicização religiosa da assistência social chega ao Brasil. As relações de cooperação entre Estado e Igreja que vigoravam no território europeu nortearam o desenvolvimento da promoção de assistência social durante toda a colonização portuguesa no Brasil. A promoção de assistência social foi, durante muito tempo, dominada por organizações ligadas à Igreja, como um efeito da configuração de poder entre a realeza e a Igreja em Portugal. O Estado delegava à Igreja essa atribuição de prover assistência a populações necessitadas. Nesse sentido, o valor da caridade cristã permaneceu central no terreno das motivações para as práticas de assistência social no Brasil desde os primórdios da colonização. Isso só começou a mudar a partir de meados do século XX, quando o predomínio do valor da caridade cristã na promoção de assistência começa a ceder 
terreno para novos valores sociais, dentro de um processo social que culminaria com a formação do campo das ONGs no final do mesmo século.

Se levarmos em consideração o longo período entre a colonização e a primeira metade do século XX, é possível identificar tendências e processos de longa duração que orientaram as relações entre Estado, Igreja e sociedade no Brasil. Em cada época histórica, o arranjo de poder distribuído entre essas três forças sociais oscilou ao sabor dos interesses dos atores e das contingências da história. Na colonização, a Igreja e o Estado celebravam um projeto missionário de parceria que atendia a interesses de ambas as partes: a legitimação da ordem e a conquista de novas almas. Esse projeto perdurou até a segunda metade do século XVIII, época das reformas pombalinas na administração do império português, quando surgiram os primeiros conflitos entre a religião e o despotismo esclarecido português. Com o advento da Independência e a transformação do Brasil em Império, o Estado reduziu ao máximo a influência da Igreja sobre a sociedade e passou a controlá-la diretamente (Souza, 2002; Lima, 1979; Bruneau, 1974). Com o fim do Império, a primeira Constituição Republicana (1891) instaura a separação entre Estado e Igreja. O Brasil é, então, declarado um Estado republicano e laico.

Ao longo do período republicano, as relações entre Estado e Igreja foram progressivamente se reequilibrando. A Igreja começava a recuperar a influência perdida desde o Império (Lima, 1979). Se, inicialmente, na primeira década após o fim do Império, a tarefa principal foi manter sua base social nas elites, ao longo das três primeiras décadas do século XX a Igreja passou a incorporar também as classes médias e intelectuais (Miceli, 2009; Paiva, 2003; Schwartzman, 1986; Cavalheiro, 1983). Ao ampliar sua base social e garantir presença em todas as camadas sociais do Brasil, a Igreja avançava a passos largos no seu projeto de recuperação de prestígio. Uma consequência não intencional desse processo se revelaria pouco tempo depois, quando setores da classe média católica conduziram uma aproximação da Igreja com as classes populares no fim da década de 1940 e durante toda a década de 1950, lançando novas direções ao 
velho processo de laicização religiosa da assistência social. O ápice desse processo ocorreu durante as décadas de 1960-70, quando esse segmento da classe média católica optou por radicalizar o engajamento político e romper formalmente com a autoridade eclesiástica para formar uma frente independente de atuação (Paiva, 2003; Semeraro, 1994; Salem, 1982; Lima, 1979). Essa opção repercutiu diretamente no âmbito das instituições de assistência, com o aparecimento de novas organizações leigas, dessa vez localizadas "fora" da Igreja, mesmo tendo sido muitas vezes originadas "dentro" dela própria. No campo da assistência social, começava a tomar forma a primeira grande transformação histórica de contribuição decisiva para a formação, alguns anos mais tarde, das modernas organizações não governamentais no Brasil.

Sustento, portanto, que o primeiro passo para a formação do campo das ONGs no Brasil foi dado através da iniciativa de algumas organizações leigas que optaram por se converter a ideologias de esquerda. A fundação da Ação Popular (AP), em 1962, foi uma experiência representativa desse processo. Essa organização foi criada como um movimento político voltado para transformação social através da educação, dentro de uma perspectiva ideológica que acomodava o humanismo cristão e o materialismo histórico. A maior parte dos membros da Ação Popular era oriunda da Ação Católica Brasileira e da Juventude Universitária Católica (JUC). A experiência da AP marcou definitivamente a história da assim chamada esquerda católica ao inaugurar uma trajetória que se tornaria comum a muitas organizações: uma origem católica sucedida por um rompimento formal com a Igreja. Progressivamente, essas organizações foram se aproximando dos movimentos sociais, deixando para trás o humanismo cristão e elegendo o socialismo como principal motivação ideológica para ação.

Embora gozassem de relativa independência da Igreja, a proximidade com os movimentos sociais ainda ameaçava a autonomia institucional dessas organizações (Landim, 1998, p. 46-7). Como visavam servir os movimentos sociais, auxiliando-os na interação com o Estado, foram chamados de centros de assessoria aos movimentos sociais. Assim, após se distanciarem da Igreja, 
essas organizações mantiveram uma proximidade com os movimentos sociais que comprometia o desenvolvimento de sua autonomia institucional enquanto ator da sociedade civil. O próprio cenário de construção da sociedade civil com o fortalecimento das organizações de base colocava em xeque os centros de assessoria. Diante de movimentos sociais cada vez mais estabelecidos e independentes, esses centros vão perdendo sua própria razão de ser. Crescia então a necessidade de definir uma identidade coletiva própria, que os tornasse independentes dos movimentos sociais. Começaram, então, a organizar uma série de congressos, encontros, debates e publicações com o objetivo de avançar na elaboração de uma identidade comum e específica dentro da sociedade civil brasileira (Oliveira, 1999, p. 58-59; Landim, 1993, p. 47-8).

O primeiro registro da palavra ONG, no Brasil, teve lugar neste contexto, em 1986, por ocasião do "Encontro Nacional de Centros de Promoção Brasileiros". Trinta dirigentes de centros de assessoria de todo o país, junto com três organizações internacionais parceiras, se reuniram para discutir a criação de uma identidade institucional para essas instituições (Landim 1993, p. 52). De modo semelhante ao que acontecera antes com relação à Igreja, as ONGs se afirmavam agora como organizações independentes dos movimentos sociais (embora ligadas a estes). Esse foi, portanto, o segundo passo importante no processo de formação do campo das ONGs no Brasil.

Se o final da década de 1980 representou o coroamento do processo de transição democrática, com a formalização de procedimentos institucionais importantes (como a promulgação da Constituição Federal de 1988), os primeiros anos da década de 1990 ficaram marcados como começo da "rotinização" da democracia no Brasil. Findo o processo de transição da ditadura para a democracia, começava então uma nova fase na vida política nacional: a legitimação do regime e das instituições democráticas no dia a dia dos cidadãos. A democracia deixava de ser uma ideia a ser perseguida para se tornar uma prática a ser aprimorada. Naquele momento, além da diversificação dos atores e dos canais de participação, a sociedade civil reformulou também suas modalidades de ação política para enfrentar os 
desafios colocados por novos temas tão variados que irromperam a cena pública, como, dentre outros, feminismo, raça, meio ambiente e AIDS. As relações da sociedade civil com as organizações de mercado também começaram a florescer nessa década, assim como as relações com os organismos internacionais governamentais e não governamentais, sendo esse, portanto, o terceiro e definitivo passo para consolidação do campo das ONGs no Brasil.

Ao longo da década de 1990, assim como aconteceu em outras regiões do mundo (Skocpol, 2003), a sociedade civil no Brasil foi se aproximando de um modelo de ativismo social que enfatizava mais a eficiência de suas ações do que o comprometimento ideológico de seus atores. Esse modelo de ativismo social era representado, sobretudo, pelas ONGs, os antigos centros de assistência aos movimentos sociais que passaram a interagir com o Estado, a sociedade civil e o mercado na promoção de serviços e assistência destinados a segmentos específicos da população. Essas organizações passaram por um processo de profissionalização, que envolveu a especialização de sua mão de obra, a formalização de seu estatuto jurídico e a diversificação das suas fontes de financiamento. Nesse período, foram intensificados os vínculos de cooperação internacional das ONGs e aumentou também o número de organizações ligadas ao mercado que atuavam em projetos sociais (Reis, 2013; Gurza-Lavalle; Bueno, 2011; Koslinski; Reis, 2009). No decorrer da década de 1990, o vocábulo ONG foi se consolidando não apenas dentro de circuitos de relações sociais e políticas específicos, mas também no contexto mais amplo das relações cotidianas no país e até mesmo no vocabulário do senso comum.

Em suma, as três grandes transformações históricas que formaram o campo das ONGs durante o século XX foram o efeito não programado do processo de laicização religiosa das práticas de assistência social no Brasil e acabaram por delimitar o escopo ideológico desse campo. Entre as décadas de 1960 e 1990, foi formado o universo simbólico dentro do qual as ONGs foram legitimadas. A diferenciação frente à Igreja, a diferenciação frente aos movimentos sociais e a consolidação identitária 
foram três condições necessárias para a formação do universo simbólico das ONGs. A transição da caridade cristã para o engajamento político e depois para a profissionalização foi um processo concomitante à transformação das organizações leigas católicas em centros de assessoria aos movimentos sociais e, finalmente, nas ONGs.

\section{A trajetória de Betinho: da militância religiosa ao ativismo laico e apartidário}

Betinho nasceu em 1935, na cidade de Bocaiúva, em Minas Gerais. Seus pais, Henrique e Maria, eram pessoas extremamente religiosas e prezavam a caridade cristã e a solidariedade como valores importantes em suas vidas. Antes do nascimento de Betinho, Henrique já praticava caridade em sua profissão de dono de padaria, quando mantinha o hábito de doação de comida aos mais pobres. Sua mãe, Maria, também tinha o hábito de preparar almoços e jantares não apenas para seus familiares, mas também para os amigos da família, estudantes de medicina que faziam residência no hospital da Santa Casa da Misericórdia, frades dominicanos da Juventude Estudantil Católica (JEC) e da JUC e diversas outras pessoas que apareciam na residência dos Souza. Tinha sete irmãos e irmãs. Dois deles eram, assim como ele, portadores da hemofilia, doença genética que compromete a coagulação sanguínea, expondo a pessoa a riscos cotidianos e demandando um tratamento rigoroso, sendo muitas vezes necessária a transfusão de sangue. Diante das limitações próprias a uma criança hemofílica, Betinho viveu uma infância relativamente difícil, mas sempre cercado pela família (Rodrigues, 2007).

Quando chegou o período de sua adolescência, a hemofilia lhe impôs restrições ainda mais severas. A fase mais traumática aconteceu entre 15 e 18 anos, período em que contraiu tuberculose. Naquela época, em 1950, a tuberculose era uma doença que praticamente condenava as pessoas à morte e apresentava alto poder de contágio. Depois de confirmado o diagnóstico, restaram duas opções à família de Betinho: enviá-lo para o 
sanatório ou isolá-lo no quartinho de fundos da casa em que morava. Eram poucas as esperanças de cura, a família já estava preparada para o pior, tendo, inclusive, convocado um padre para lhe conceder a extrema-unção. Os pais resolveram mantê-lo em casa. Instalaram uma campainha que ligava o quarto às outras dependências. Durante os três anos de reclusão, Betinho passava a maior parte do tempo lendo livros e revistas e fazendo cursos à distância (Souza, 1976).

As leituras dos católicos franceses durante o período de reclusão reforçaram sua crença religiosa e, mais do que isso, incentivaram-no a viver a religião como uma forma de engajamento político, seguindo o exemplo das três irmãs que já militavam na Ação Católica. Logo após a cura da tuberculose, Betinho começou a comungar diariamente e foi atrás do "tempo perdido", na escola e na militância católica. Convencido de que a cura fora uma compensação divina à sua rígida postura religiosa, Betinho retoma os estudos secundários e decide ingressar na Ação Católica e também no movimento estudantil através da Juventude Estudantil Católica (JEC). Seu carisma, suas leituras e sua história de vida o credenciaram a coordenar a liderar as atividades da JEC. Para ele, o mais importante nessa época era compensar o período em que ficou recluso sem poder fazer militância (Rodrigues, 2007, p. 53; Souza, 1976, p. 69).

Diferentemente da visão tradicional do cristianismo, que apresentava Cristo como uma figura assexuada, desligada e mística, os ativistas da JEC defendiam a ideia de um Cristo revolucionário, forte e proativo. Essa nova percepção de Cristo ajudou os militantes a reformularem a visão tradicional que tinham do cristianismo. Ao invés de impotência e castração, a religião passou a ser percebida como uma força propulsora, que os impelia à ação e à transformação do mundo (Souza, 1976, p. 70). A interpretação religiosa do mundo passava a incorporar o valor da justiça social como uma referência importante. O cristianismo procurava dialogar com o marxismo. Estava aí plantado o movimento que, anos mais tarde, culminaria na formação da teologia da libertação. Betinho participou ativamente da JEC desde que retomou os estudos secundários após a cura da tuberculose. Terminado o 
ensino médio, Betinho ingressou nos cursos de administração pública e de sociologia política da Faculdade de Ciências Econômicas (FACE), em 1958.

À medida que crescia seu envolvimento com a militância política, no final da década de 1950 e começo da década de 1960, diminuía o envolvimento com a religião. Isso acontecia não apenas com ele, mas com boa parte das pessoas que começaram sua militância política dentro da Igreja. A religião deixava de ser uma prioridade para essas pessoas e se tornava algo até mesmo secundário se comparada com seus compromissos com o ideal da justiça social. A política passava a ser a lente através da qual eles interpretavam o mundo, tratavam da política pela política e não mais pela religião. Certamente, o fato de muitas pessoas terem passado pela mesma transformação não significa que elas o tenham feito exatamente da mesma maneira. Neste ponto, o caso de Betinho é muito mais a exceção do que a regra. A opção mais recorrente foi a de viver uma relação de ambivalência com a religião, isto é, quando a mesma é deslocada da vida pública, mas permanece recôndita na vida privada. No caso de Betinho, a religião foi expurgada tanto da sua vida pública quanto privada.

Essa transformação não aconteceu da noite para o dia. O afastamento da religião ocorreu mediante um longo processo de transição, que só terminou depois dos trinta anos de idade. Gradualmente, o trabalho de militância política vai entrando em contradição com os preceitos católicos que vigoravam dentro dos espaços institucionais em que ele atuava, como a JUC, a Ação Católica e a Ação Popular. O ato sexual, por exemplo, deixa de ser apenas um meio para a reprodução (Rodrigues, 2007, p. 88-9). Betinho começa a namorar com Irles, aquela que se tornaria sua primeira esposa e mãe do primeiro filho. Além de toda essa mudança comportamental com relação à atividade sexual, o abandono da religião também foi acompanhado por uma recusa a toda e qualquer outra forma de dogmatismo. As sessões de psicanálise e os acontecimentos vivenciados entre o começo da década de 1960 e o começo da década de 1970 fizeram Betinho mudar radicalmente sua concepção de ação histórica. Cada vez mais ele passava a minimizar o sentido missionário e voluntarista das ações de esquerda: 
A primeira coisa que descobri foi a perda do sentido missionário. Olha, eu não sou nenhum dos doze apóstolos, nem o décimo terceiro. Descobri que sou um cidadão comum e corrente. Que não tenho a missão e dever de estar convencendo ninguém a entrar em meu apostolado. Estou exatamente para liquidar com essa visão religiosa do revolucionário como um apóstolo. Acho que o dia em que chegar o momento em que vamos participar de um processo não vai ser porque um chamou ou teve a ideia, mas porque uma necessidade objetiva nos vai colocar na situação de trabalharmos juntos (Souza, 1976, p. 102).

Assim como a vinculação religiosa nos jogou no movimento estudantil, o movimento estudantil nos jogou na política nacional. Ao crescer esse movimento de participação, a religião já não dizia mais nada. Passamos então de uma visão religiosa a uma perspectiva política. Só que passávamos à política com a mesma mística que havíamos vivido na religião, a mesma perspectiva de compromisso, a mesma pureza, responsabilidade, auto-renúncia. É claro, a própria prática dirigia o nosso conhecimento para uma amplitude maior, para o marxismo (Souza, 1976, p. 71).

Após o golpe militar em 1964, os militantes da AP foram perseguidos pelos militares. Em 1965, Betinho partiu para o exílio e voltou um ano depois. Assumiu identidade falsa, teve um filho com Irles e separou-se dela. Em 1971, Betinho partiu para uma longa temporada no exílio: primeiramente Chile e depois Canadá e México. No momento de partida para esse segundo exílio, suas convicções ideológicas já haviam mudado bastante. Betinho passou então a avaliar negativamente tanto as ações da AP quanto seu engajamento com a organização. Em parte magoado por um rebaixamento institucional e em parte desiludido com as referências ideológicas em voga na $\mathrm{AP}$, Betinho passou a criticar duramente o centralismo democrático e o dogmatismo que imperavam na organização (Rodrigues, 2007, p. 115). No momento que decidiu romper com a AP e partir para o exílio, ele fechava um ciclo que havia começado no seu envolvimento com o movimento estudantil universitário, no final da década de 1950. No exílio, se uniu a Maria Nakano, militante da AP, com quem viveu uma história de amor que duraria longos 27 anos, até sua morte. 
Após o anúncio da anistia no Brasil, em setembro de 1979, Betinho decidiu retornar com o ânimo renovado pela possibilidade de, enfim, voltar a fazer política em seu país natal. Uma vez no Brasil, tratou de logo retomar suas atividades políticas. Era como "um segundo despertar", ainda mais poderoso do que aquele vivenciado aos 18 anos, quando saíra da reclusão médica em razão da tuberculose (Souza, 1994, p. 14; 1976, p. 69). Dessa vez, ao invés da militância católica, seu farol dentro da política era o próprio valor da democracia. Betinho fundou e ajudou a fundar uma série de instituições com o objetivo de fortalecer a sociedade civil brasileira, que também despertava de um sono profundo que durou todo o regime militar. Sua experiência no exterior, as pessoas que conheceu e as instituições por que passou foram ingredientes fundamentais na fundação das organizações que viriam a se tornar as primeiras ONGs do Brasil. Uma das principais contribuições de Betinho nesse processo foi fundar, junto com Carlos Afonso e Marcos Arruda, o Instituto Brasileiro de Análises Sociais e Econômicas (IBASE), uma instituição chave no processo de formação do campo das ONGs no Brasil, estando, inclusive, entre as instituições organizadoras do evento de 1986 que consagrou a expressão ONG.

Um dos capítulos mais dramáticos na vida de Betinho após o retorno ao Brasil foi sua luta contra a AIDS. Apesar de passar toda a vida com uma saúde bastante debilitada, foi a experiência com a doença que trouxe o sentido da morte para mais perto de Betinho, afetando em cheio seu cotidiano. Acelerou seus planos de casamento com Maria, que ocorreu em uma cerimônia dentro do IBASE, buscando evitar deixá-la desamparada após sua morte (Rodrigues, 2007, p. 191-2). Como sempre acontecera em sua vida, Betinho elevou sua experiência pessoal com a AIDS para o nível público do seu engajamento político. Agora, o papel de militante da democracia se confundia com o papel de porta-voz e defensor das pessoas contaminadas pelo vírus HIV, fazendo ressurgir nele o sentido missionário que havia enterrado com seu desligamento da AP. Fundou então a Associação Brasileira Interdisciplinar sobre AIDS (ABIA) com o objetivo de ampliar a 
discussão sobre a doença para além do âmbito da medicina, incorporando também o âmbito da política, da cidadania e das relações sociais.

Após ter sobrevivido à tuberculose, à hemofilia, à repressão e ao exílio, a AIDS representava então mais um desafio a ser vencido na vida de Betinho, e assim o foi. A doença não o impediu de continuar sua militância política, pelo contrário. Além do engajamento na própria questão da AIDS, Betinho se lançou também no combate à corrupção, na luta pela democratização das informações e na luta contra a fome e a miséria. Essa última causa talvez seja aquela em que ele mais triunfou. Além da luta pessoal contra a AIDS, a campanha nacional contra a fome e a miséria projetaram sua já conhecida figura a um nível de popularidade ainda mais elevado. Em 1993, Betinho montou uma campanha social que entraria para a história do Brasil, articulando atores diversos no âmbito da sociedade civil, do Estado e do mercado, todos contra a fome e a miséria. A campanha intitulada "Ação da cidadania contra a miséria e pela vida" representou um marco na história do voluntariado e da formação do campo das ONGs. Nos últimos anos de vida, Betinho já era um dos brasileiros mais conhecidos de seu tempo. Tamanha popularidade Ihe rendeu diversos convites para assumir cargos públicos no Estado, a maior parte deles recusados.

A ação da cidadania foi uma campanha de doação de alimentos não perecíveis para combater o problema da fome no Brasil. Através de um forte aparato midiático, sobretudo televisivo, a "campanha do Betinho" (como ficou popularmente conhecida a Ação da cidadania) conclamou a população brasileira a organizar comitês de arrecadação de alimentos. Apesar de ser ligada à figura de Betinho, a campanha seguiu um modelo descentralizado de organização: não era preciso nenhuma espécie de autorização para a formação dos comitês, cada grupo decidia o quê e como fazer para se engajar na luta contra a fome (Pinto, 2005; Fico, 1999). Um número cada vez maior de pessoas se dispusera a agir em prol dos famintos, movidos, sobretudo, por sentimentos de indignação e compaixão, marcas da campanha. Cidadãos, famílias, grupos de amigos, escolas, vizinhos, igrejas, artistas, empresas, fundações, ONGs, sindicatos, autarquias e até mesmo 
presidiárias, praticamente toda a sociedade brasileira se mobilizou para combater o problema da fome no país. Nunca uma campanha conseguira articular tantas pessoas e potencializar tantos resultados.

Em dezembro de 1993, o IBOPE divulgou em pesquisa que 68\% dos brasileiros declaravam conhecer a campanha de Betinho e 32\% participaram ou contribuíram para esta campanha (Rodrigues: 2007, p. 211; Jornal do Brasil, 1997; Landim, 1993, p. 242). Vale lembrar que a campanha não fez uso de centrais computadorizadas para doações através de telefone por entender que esse modelo eliminaria a participação direta das pessoas (Landim, 1998, p. 256). Levando em consideração o número relativamente reduzido de brasileiros que se envolvem com atividades voluntárias (menor ainda quando se trata de filantropia), esses resultados são surpreendentes. Em 2001, por exemplo, o Instituto Datafolha divulgou pesquisa em que $73 \%$ dos brasileiros afirmam nunca ter participado de instituições ou campanhas como voluntário prestando serviços para a comunidade (Datafolha, 2001). Dez anos depois, o IBOPE divulgou pesquisa que corrobora esses números: 25\% dos brasileiros afirmaram já ter feito trabalho voluntário (IBOPE, 2011). Se cruzarmos esse dado sobre a estabilidade no percentual de voluntários com os dados sobre participação na Ação da Cidadania, quando se estimou a participação de 32\% dos brasileiros, é possível ter uma noção precisa sobre o amplo alcance dessa campanha. Em 1993, possivelmente todas as pessoas que fizeram alguma ação voluntária no Brasil participaram da campanha da Ação da cidadania, uma campanha que, portanto, mobilizou de forma inédita praticamente todo o voluntariado nacional.

A luta contra a fome e a miséria no Brasil foi um combustível importante para o engajamento de Betinho no universo das ONGs e consiste em um ponto de inflexão importante no seu ativismo. Antes disso, o principal tema de militância de Betinho foi, primeiro, o cristianismo e, depois, a democracia. Quando encerrou suas atividades na AP, Betinho também abandonou uma série de convicções que norteavam sua visão de mundo: o marxismo, a luta armada, o sentido missionário, o centralismo democrático etc. Por sua vez, durante o tempo em que permaneceu no exílio, Betinho procurou retomar 
a profissão de sociólogo para abordar novos temas de seu interesse, como a reforma agrária e as transformações do Estado. Esse foi, justamente, o período em que ele assumiu mais a condição de intelectual. Quando retornou ao Brasil, Betinho estava ansioso para aplicar o conhecimento adquirido no exílio e retomar sua atuação política. Assim, é possível estabelecer uma relação direta entre a prática ou vivência profissional e a formação ideológica em sua trajetória (Souza, 2001; 1994). As imagens do Betinho religioso, revolucionário, sociólogo e líder de ONGs correspondem a etapas diversas de sua vida, momentos em que ele exerceu atividades distintas, como, respectivamente, missionário, líder de organizações políticas, professor e ativista.

Betinho morreu em 1997, pouco antes de completar 62 anos, no apartamento em que vivia com Maria, cercado por vinte amigos escolhidos por ele próprio. Ciente da proximidade da morte, tomou suas últimas decisões: deixou uma carta emocionada para ser entregue à companheira após sua partida e pediu que fossem retiradas todas as velas, crucifixos e demais símbolos religiosos em seu velório (Souza, 2001, p. 68). Betinho foi marcado por uma trajetória de vida extremamente ambivalente, repleta de dilemas e contradições entre a religião e a política, a família e a militância, a esperança e o medo, a vida e a morte.

Transitando por dentro dos domínios entrecruzados de sua vida pública e sua vida pessoal, a trajetória de Betinho traduz com notável correspondência os grandes acontecimentos que marcaram a formação do campo das ONGs no Brasil. Após uma educação extremamente religiosa na infância e adolescência, sua juventude foi marcada por forte comprometimento religioso e engajamento político. Contudo, o envolvimento com a política acabou por desestabilizar as convicções religiosas de Betinho, que então renegou a Igreja e se declarou ateu. Partiu para o exílio durante a ditadura militar. Ao retornar, fundou ONGs que foram fundamentais para a formação do campo, como, dentre outras, o IBASE, a ABIA e o Viva Rio. As origens religiosas e o rompimento com a Igreja, a procura por uma identidade ideológica/institucional independente e a popularização do engajamento 
cívico são características que poderiam ser atribuídas tanto ao processo de formação do campo das ONGs do Brasil em geral quanto à trajetória particular de seu principal agente. Dito de outro modo, a história de vida de Betinho oferece contornos individualizados ao processo geral de transformação da caridade católica na militância política. Neste sentido, por contemplar todas as três etapas de transformação do campo, o pioneirismo de Betinho é tomado aqui como arquétipo através do qual podem ser interpretadas as várias formas de agência que conduziram o processo de formação do campo das ONGs.

\section{Conclusão: Betinho e as ONGs em um jogo de espelhos}

O fato de a trajetória singular de Betinho resumir as três transformações da formação do campo das ONGs no Brasil é suficiente para tomá-la como uma espécie de arquétipo das trajetórias individuais que constroem o campo. Um arquétipo que serve como referência ou padrão para comparação e não como um modelo monolítico. Nesse sentido, a trajetória de Betinho revela um dos muitos encaminhamentos possíveis nas questões com que ele se deparou. Se as questões são mais ou menos as mesmas para todos, o modo como cada um responde é singular. O modo como cada agente reagiu ao desafio de autonomização da política frente a religião, por exemplo, foi extremamente variado.

A vida de Betinho condensa dentro de uma mesma trajetória individual todas as três grandes transformações históricas que foram analisadas na segunda seção deste artigo. A forte influência da religião em sua infância, na juventude e no começo da vida adulta, seguida pela negação dessa mesma influência no restante de sua vida é uma condição semelhante à experiência de formação das ONGs no Brasil, que nasceram dentro da Igreja, mas se desenvolveram para fora dela. Seu protagonismo na criação de instituições importantes e influentes foi crucial durante a segunda grande transformação do campo das ONGs, assim como sua luta contra a AIDS e contra a fome no Brasil, que foi também decisiva na terceira transformação. 
De fato, na trajetória individual de Betinho é possível observar o processo macro histórico de formação do campo das ONGs no Brasil sobre um plano subjetivo.

Como foi mencionado, Betinho recusou muitos convites para assumir cargos públicos. No fim de 1992, por exemplo, por indicação de Luís Inácio Lula da Silva, o então presidente da República Itamar Franco convidou Betinho para dirigir o recém-criado Conselho Nacional de Segurança Alimentar (CONSEA). O convite foi prontamente recusado por Betinho, que alegou "problemas de saúde e ojeriza a cargos governamentais" (Fico, 1999, p. 126). Ao longo de sua trajetória, portanto, foi consolidando um ceticismo com relação à religião, à ideologia, à política partidária e até mesmo a cargos públicos. O que, no entanto, não esmoreceu foi sua gana para "fazer alguma coisa", para romper com o ceticismo generalizado nas ideologias e instituições e oferecer algum tipo de contribuição substantiva na política. A junção desse ceticismo nas instituições com a vontade de mudar a realidade obrigou Betinho a reinventar muitas vezes o sentido do seu ativismo político. Ele foi um pioneiro na forma de recriar laços de emoção com a política fora dos espaços mais convencionais de militância e representação. A ideia de encampar causas genéricas e pouco usuais na agenda política, como, por exemplo, a defesa dos direitos de pessoas soropositivas, antecipou formas de engajamento político que se desenvolveriam aceleradamente a partir do fim da década de 1990.

Em suma, a trajetória de Betinho individualiza e imprime contornos carnais a transformações estruturais profundas na vida política nacional, tanto no que diz respeito a suas instituições quanto à cultura política. A formação do campo das ONGs foi um resultado não programado desse processo e possui relações umbilicais com a formação do ativismo político de Betinho. Tão forte foi a conexão entre sua vida pessoal e a emergência das ONGs no Brasil que, mesmo se nunca tivesse nascido, uma trajetória como a dele poderia, ainda assim, ter sido criada por um cientista social como um tipo ideal que cristaliza em um percurso individual um conjunto variado de transformações de âmbito estrutural. 
Fernando Lima Neto é Doutor em Sociologia e Professor Adjunto no Departamento de Ciências Sociais e no Programa de Pós-Graduação em Ciências Sociais da PUC-Rio. $\equiv$ fercaline@gmail.com.

\section{Referências}

1. AVRITZER, Leonardo. Sociedade civil, instituições participativas e representação: da autorização à legitimidade das ações. Dados, v. 50, n. 3, p. 443-64, 2007.

2. BOBBIO, Noberto; BOVERO, Michelangelo. Sociedade e Estado na filosofia política moderna. São Paulo: Brasiliense, 1996.

3. BRUNEAU, Thomas. O catolicismo brasileiro em época de transição. São Paulo: Loyola, 1974.

4. CARVALHEIRA, Marcelo P. D. Momentos históricos e desdobramentos da Ação Católica Brasileira. Revista Eclesiástica Brasileira, v. 43, n. 169, p. 10-28, 1983.

5. CORREIA, Fernando da S. Origens e formação das Misericórdias Portuguesas. Lisboa: Livros Horizonte, 1999.

6. CROZIER, Michel; HUNTINGTON, Samuel; WATANUKI, Joji. The crisis of democracy. Report on the governability of democracies to the Trilateral Commission. Nova York: New York University Press, 1975.

7. DATAFOLHA. Pesquisa voluntariado. São Paulo: Datafolha, 2001.

8. ELIAS, Norbert. Mozart: a sociologia de um gênio. Rio de Janeiro: Jorge Zahar, 1995.

9. FICO, Carlos. Ibase: usina de ideias e cidadania. Rio de Janeiro: Garamond, 1999.

10. GURZA-LAVALLE, Adrian; BUENO, Natália. Waves of change within civil society in Latin America. Politics \& Society, v. 39, n. 3, p. 415-50, 2011.

11. GURZA-LAVALLE, Adrian; HOUTZAGER, Peter; CASTELLO, Graziella. Representação política e organizações civis: novas instâncias de mediação e os desafios da legitimidade. Revista Brasileira de Ciências Sociais, v. 21, n. 60, p. 43-66, 2006.

12. HOBBES, Thomas. Leviatã. São Paulo: Martins Fontes, 2014.

13. IBOPE. Pesquisa perfil do voluntariado no Brasil. Rio de Janeiro: IBOPE, 2011.

14. KECK, Margareth; SIKKINK, Kathryn. Transnational advocacy networks in international and regional politics. International Social Science Journal, v. 51, n. 1, p. 89-101, 1999.

15. KOSLINSKI, Mariane; REIS, Elisa. Transnational and domestic relations of NGOs in Brazil. World development, n. 37, p. 714-25, 2009. 
16. LANDIM, Leilah (Org.). Ações em sociedade: militância, caridade, assistência etc. Rio de Janeiro: NAU, 1998.

17. LANDIM, Leilah. Para além do Estado e do mercado? Filantropia e cidadania no Brasil. Rio de Janeiro: ISER, 1993.

18. LIMA-NETO, Fernando. L'invention des ONG au Brésil: la sociogènese des idéaux et des acteurs fondateurs. Paris: Éditions Recherches, 2016.

19. LIMA, Luiz G. de S. Evolução política dos católicos e da igreja no Brasil: hipóteses para uma interpretação. Petrópolis: Vozes, 1979.

20. MACADAM, Doug; MCCARTHY, John; ZALD, Mayer (Orgs.). Comparative perspectives on social movements: political opportunities, mobilizing structures and cultural framings. Nova York: Cambridge, 1996.

21. MANIN, Bernard. As metamorfoses do governo representativo. Revista Brasileira de Ciências Sociais, v. 29, n.10, p. 5-34, 1996.

22. MESGRAVIS, Laima. A Santa Casa da Misericórdia de São Paulo. São Paulo: Conselho Estadual de Cultura, 1976.

23. MICELI, Sergio. A elite eclesiástica brasileira: 1890-1930. São Paulo: Companhia das Letras, 2009.

24. MIGUEL, Luis F. Democracia e representação. São Paulo: UNESP, 2014.

25. MOISÉS, José Á. (Org.). Democracia e confiança: por que os cidadãos desconfiam das instituições públicas? São Paulo: Edusp, 2010.

26. JORNAL DO BRASIL. Morre Betinho: a voz maior da cidadania. Jornal do Brasil, 9 ago. 1997.

27. NEYRON, Gustave. Histoire de la charité, le christianisme en action. Paris: S.P.E.S., 1927.

28. OLIVEIRA, Miguel. Cidadania e globalização: a política externa brasileira e as ONGs. Brasília: Instituto Rio Branco, 1999.

29. PITKIN, Hannah. Representação: palavras, instituições e ideias. Lua Nova, v. 67, p. 15-47, 2006.

30. PAIVA, Angela R. Católico, protestante, cidadão: uma comparação entre Brasil e Estados Unidos. Belo Horizonte: Ed. UFMG/IUPERJ, 2003.

31. PINTO, Celi. A sociedade civil e a luta contra a fome no Brasil (1993-2003). Sociedade e Estado, v. 20, n. 1, p. 195-228, 2005.

32. REIS, Elisa (Org.). ONGs: novos vínculos entre a sociedade e o Estado. Rio de Janeiro: 7 Letras, 2013.

33. RODRIGUES, Carla. Betinho: sertanejo, mineiro, brasileiro. São Paulo: Planeta, 2007.

34. RUSSELL-WOOD, Anthony J. Fidalgos e filantropos: a Santa Casa da Misericórdia da Bahia, 1550-1755. Brasília: Ed. UnB, 1981. 
35. SALEM, Tânia. Do Centro D. Vital à Universidade Católica. In: SCHWARTZMAN, Simon (Org.). Universidades e instituições científicas no Rio de Janeiro. Brasília: Conselho Nacional de Desenvolvimento Científico e Tecnológico, 1982.

36. SCHWARTZMAN, Simon. A política da Igreja e a educação: o sentido de um pacto. Religião e Sociedade, v. 13, n. 1, p 108-27, 1986.

37. SEMERARO, Giovanni. A primavera dos anos 60: a geração de Betinho. São Paulo: Ed. Loyola, 1994.

38. SKOCPOL, Theda. Diminished democracy: from membership to management in American civic life. Norman: University of Oklahoma Press, 2003.

39. SOUZA, Ney. Os caminhos do padroado na evangelização do Brasil. Revista Eclesiástica Brasileira, v. 247, p. 683-94, 2002.

40. SOUZA, Herbert J. de. Estreitos nós: lembranças de um semeador de utopias. Rio de janeiro: Garamond, 2001.

41. SOUZA, Herbert J. de. Revoluções de minha geração: depoimento a François Bougon. São Paulo: Ed. Moderna, 1994.

42. SOUZA, Herbert J. de. Depoimento. In: CAVALCANTI, Pedro C; RAMOS, Jovelino (Orgs.) Memórias do exílio: Brasil 1964 - 19??. São Paulo: Livramento, 1976.

43. VEILLEUX, Armand. La liturgie dans le cénobitisme pachômien au quatrième siècle. Studia Anselmiana, v. 57. Roma: Libreria Herder, 1968. 